University of Wollongong

Research Online

Australian Institute for Innovative Materials -

Papers

Australian Institute for Innovative Materials

$1-1-2015$

Protein nanorings organized by poly(styrene-block-ethylene oxide) selfassembled thin films

Jenny Malmström

University of Auckland

Akshita Wason

University of Canterbury

Fergus Roache

University of Auckland

N. Amy Yewdall

University of Canterbury

Mazdak Radjainia

University of Auckland

See next page for additional authors

Follow this and additional works at: https://ro.uow.edu.au/aiimpapers

Part of the Engineering Commons, and the Physical Sciences and Mathematics Commons

Research Online is the open access institutional repository for the University of Wollongong. For further information contact the UOW Library: research-pubs@uow.edu.au 


\title{
Protein nanorings organized by poly(styrene-block-ethylene oxide) self- assembled thin films
}

\begin{abstract}
This study explores the use of block copolymer self-assembly to organize Lsm $\alpha$, a protein which forms stable doughnut-shaped heptameric structures. Here, we have explored the idea that 2-D crystalline arrays of protein filaments can be prepared by stacking doughnut shaped Lsma protein into the poly(ethylene oxide) blocks of a hexagonal microphase-separated polystyrene-b-polyethylene oxide (PS-b-PEO) block copolymer. We were able to demonstrate the coordinated assembly of such a complex hierarchical nanostructure. The key to success was the choice of solvent systems and protein functionalization that achieved sufficient compatibility whilst still promoting assembly. Unambiguous characterisation of these structures is difficult; however AFM and TEM measurements confirmed that the protein was sequestered into the PEO blocks. The use of a protein that assembles into stackable doughnuts offers the possibility of assembling nanoscale optical, magnetic and electronic structures.
\end{abstract}

\section{Keywords}

nanorings, organized, poly, styrene, films, block, protein, ethylene, oxide, self, assembled, thin

\section{Disciplines}

Engineering | Physical Sciences and Mathematics

\section{Publication Details}

Malmström, J., Wason, A., Roache, F., Yewdall, N., Radjainia, M., Wei, S., Higgins, M. J., Williams, D. E., Gerrard, J. A. \& Travas-Sejdic, J. (2015). Protein nanorings organized by poly(styrene-block-ethylene oxide) self-assembled thin films. Nanoscale, 7 (47), 19940-19948.

\section{Authors}

Jenny Malmström, Akshita Wason, Fergus Roache, N. Amy Yewdall, Mazdak Radjainia, Shanghai Wei, Michael J. Higgins, David Williams, Juliet A. Gerrard, and Jadranka Travas-Sejdic 


\section{Nanoscale}
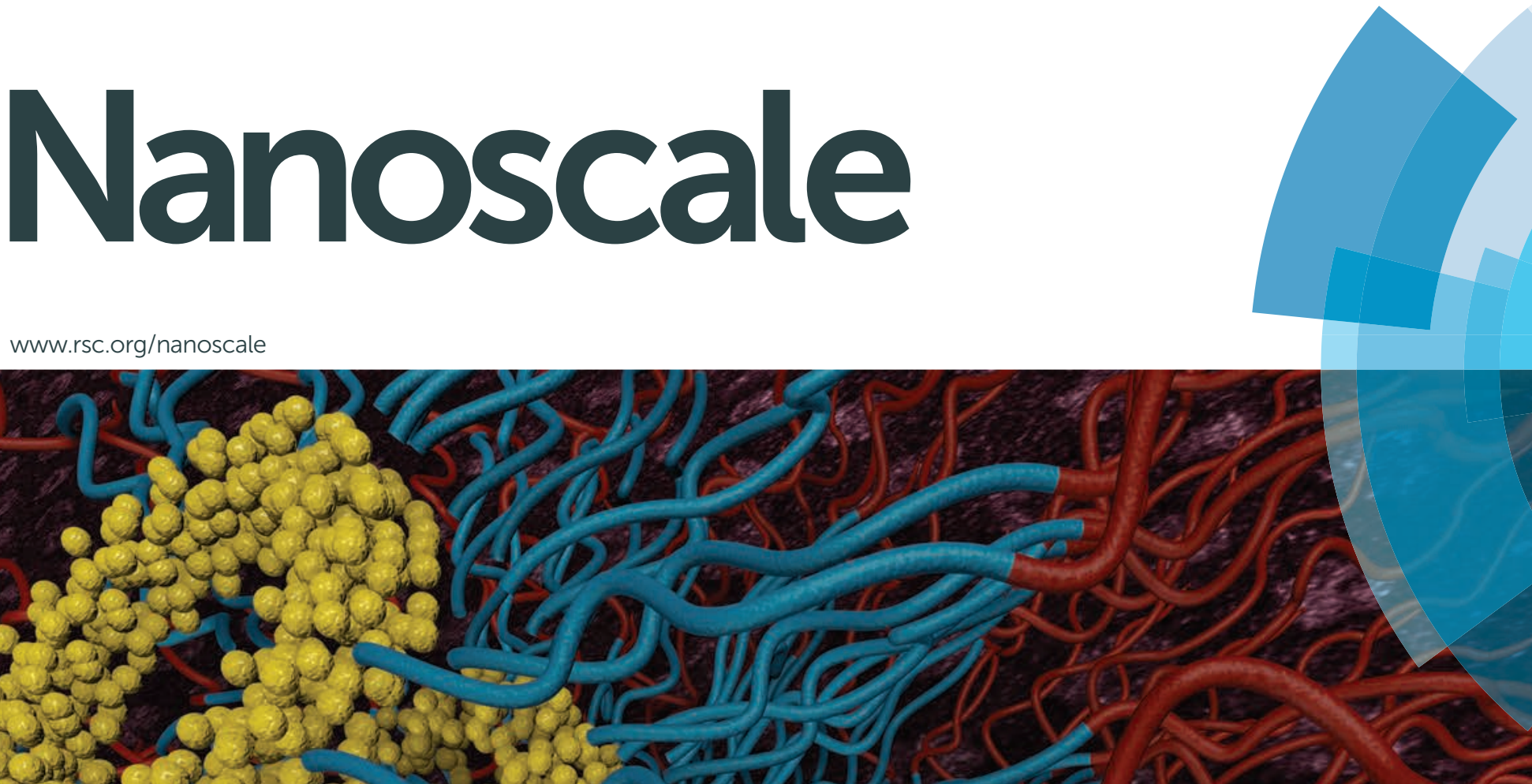

a. 3,2

Q. 2010

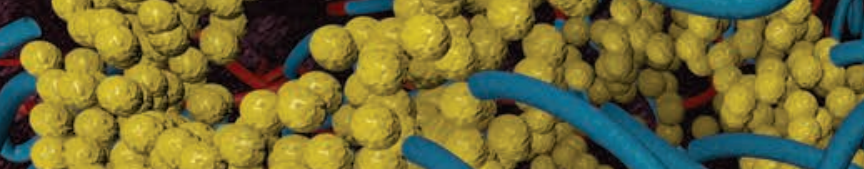

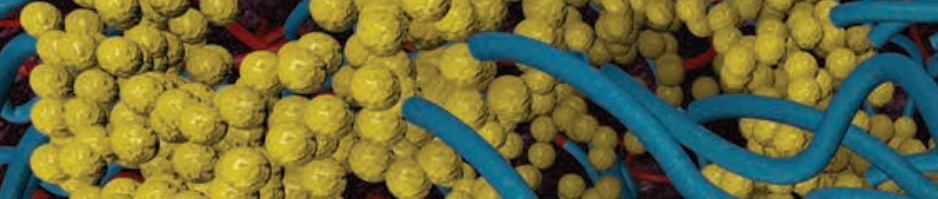

ISSN 2040-3364

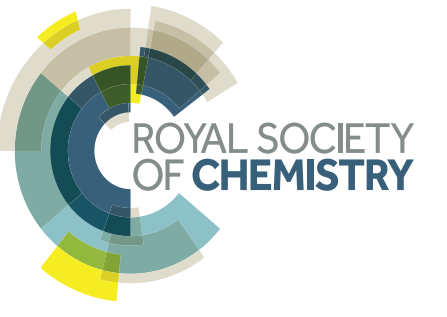

\section{PAPER}

Jenny Malmström et al.

Protein nanorings organized by poly(styrene-block-ethylene oxide) self-assembled thin films

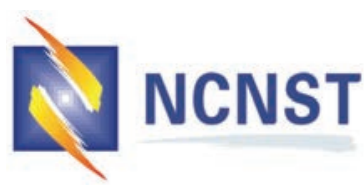




\title{
Nanoscale
}

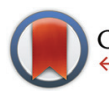

CrossMark \&lick for updates

Cite this: Nanoscale, 2015, 7, 19940

\section{Protein nanorings organized by poly(styrene- block-ethylene oxide) self-assembled thin films $\dagger$}

\author{
Jenny Malmström, ${ }^{* a, b}$ Akshita Wason, ${ }^{c}$ Fergus Roache, ${ }^{a, b}$ N. Amy Yewdall, \\ Mazdak Radjainia, ${ }^{e}$ Shanghai Wei, ${ }^{f}$ Michael J. Higgins, ${ }^{9}$ David E. Williams, ${ }^{a, b}$ \\ Juliet A. Gerrard ${ }^{a, e}$ and Jadranka Travas-Sejdic ${ }^{a, b}$
}

This study explores the use of block copolymer self-assembly to organize Lsma, a protein which forms stable doughnut-shaped heptameric structures. Here, we have explored the idea that 2-D crystalline arrays of protein filaments can be prepared by stacking doughnut shaped Lsm $\alpha$ protein into the poly(ethylene oxide) blocks of a hexagonal microphase-separated polystyrene-b-polyethylene oxide (PS$b$-PEO) block copolymer. We were able to demonstrate the coordinated assembly of such a complex hierarchical nanostructure. The key to success was the choice of solvent systems and protein functionalization that achieved sufficient compatibility whilst still promoting assembly. Unambiguous characterisation of these structures is difficult; however AFM and TEM measurements confirmed that the protein was sequestered into the PEO blocks. The use of a protein that assembles into stackable doughnuts offers the possibility of assembling nanoscale optical, magnetic and electronic structures.

Received 12th August 2015,

Accepted 14th October 2015

DOI: $10.1039 / c 5 n r 05476 a$

www.rsc.org/nanoscale nanotechnology due to their versatility, small size and precise control over self-assembly. In the context of block copolymers, incorporation of biomolecules heralds a new domain of novel functional materials. DNA origami pioneered the field of using the inherent recognition and folding of biomolecules as building blocks in complex assemblies. ${ }^{20-22}$ Proteins exist with an enormous structural and chemical versatility and lend themselves better to be functionalized with different moieties than DNA. ${ }^{23}$ The ability to rationally engineer proteins enables the use of proteins as carefully designed nanometer sized building blocks. ${ }^{24}$ The main challenge facing the field of protein nanotechnology is the ability to control proteinprotein interactions to build up higher order structures, and in particular to order these structures. Previous work on creating protein assemblies has been largely centered around amyloid fibers $^{25-29}$ but has recently also involved native protein structures ${ }^{30-32}$ with ring shaped proteins emerging as a commonly used self-assembling feature. ${ }^{33-37}$ Recent work has established methods to post functionalize assembled structures, ${ }^{38,39}$ an important step towards applications based on protein nanostructures.

There is intense interest in "one-dimensional nanostructures". Controlled patterning and alignment of nanostructures is critical for both the study of the properties of such structures and the incorporation into devices. By using block copolymers to template proteins, we aim to develop methods for the creation of spatially well-defined patterns of protein structures, with scope for post functionalization leading to structures of a size range not otherwise accessible 


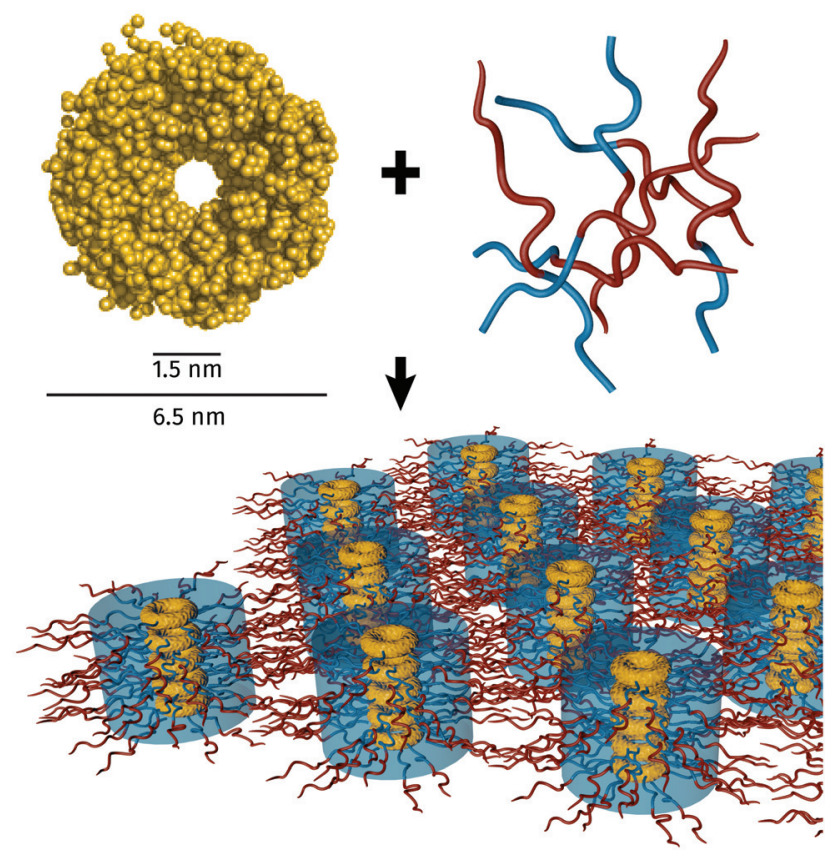

Scheme 1 Illustration of the sample preparation process. Lsm $\alpha$ (top left) is mixed with PS- $b$-PEO (top right) and spin coated into thin films with the protein sequestered into the PEO domains.

through block copolymers alone. We seek here to harness the unique features of a protein, Lsm $\alpha$ from Methanobacterium thermoautotrophicum, which was selected for its thermostability and ability to self-assemble into a heptameric ring. ${ }^{40,41}$ Proteins like Lsm $\alpha$ and peroxiredoxin ${ }^{36}$ self-assemble into robust doughnuts whose pore size can be tuned specifically to encapsulate metal complexes or nanoparticles ${ }^{37}$ and then assemble further into tunnels to create magnetic, electrical or optical nanorods. Accordingly, we have explored the possibility of using self-assembled block copolymers as scaffolds to create regular arrays of such doughnut tunnels. Poly(styrene-blockethylene oxide) (PS- $b$-PEO, $M_{\mathrm{n}} \times 10^{3} 18.0-b$-7.5) is used in this study and forms solvent-induced ordered films of hexagonally packed vertical cylinders of PEO, into which we aim to assemble the protein (Scheme 1). This polymer has not only been shown to be very robust in forming the desired phase, ${ }^{42}$ but has also been used previously for co-assembly with both peptides $^{11}$ and protein-polymer conjugates such as ferritin ${ }^{9}$ and myoglobin. ${ }^{11}$ For the protein used in this study unambiguous characterisation of these structures is difficult; however in this work we provide extensive AFM and TEM imaging which confirm the successful incorporation of the protein into the PEO blocks and thus constitute a highly ordered and functionalisable matrix with potential downstream applications in advanced materials.

\section{Results and discussion}

To form hexagonally ordered domains of PEO in PS matrix with an orientation normal to the surface, a neutral solvent is required. After spin coating of the polymer into thin films, annealing (solvent vapor ${ }^{43,44}$ or elevated temperature ${ }^{45}$ ) is needed to achieve ordered structures. A significant body of work on suitable solvents for PS- $b$-PEO ${ }^{42,43,46-49}$ exists and benzene, ${ }^{42-44}$ toluene, ${ }^{46,48}$ dimethylformamide ${ }^{9}$ and tetrahydrofuran ${ }^{47}$ have all been successfully used to produce thin films of PS- $b$-PEO in the hexagonal cylindrical phase. Solvent annealing has proved very successful for the creation of long range ordered films of PS- $b$-PEO, where the water content in the solvent vapor (toluene or benzene), plays a critical role for the phase formed. ${ }^{43,50-52}$ We used benzene as the base solvent for this study, as we found superior ordering of the films under conditions used to co-solubilize the protein and the polymer. The mixed solvent system, however, did result in some sensitivity to substrate surface chemistry, with gold producing well-ordered films of PS- $b$-PEO, but with the more hydrophilic glass or silicon wafer generating samples with defects (data not shown).

In order to solubilize the Lsm $\alpha$ protein in the spincoating polymer mixture, the protein was PEGylated. The PEG-chains serve to provide a hydrophilic shell around the protein, which captures water and protects the protein in the benzene spincoating mixture (for details see ESI Fig. S1 $\dagger$ ). The PEGylated protein was subsequently dialysed to water and freeze-dried before co-dissolving with the block copolymer. In order to protect the protein from denaturation, we followed the work by Presley et al., ${ }^{11}$ who demonstrated the success of a mixed solvent system incorporating water, methanol and benzene. Using a similar protocol, a small amount of methanol/water mix was first added to the dry protein, followed by more methanol and finally the PS- $b$-PEO (1\% in benzene), resulting in a completely clear solution (solvent composition $71.7 \%$ benzene, $26.9 \%$ methanol and $1.4 \%$ water, denoted control solvent). The final protein concentration in the solution was $\approx 0.5 \mathrm{mg} \mathrm{ml}^{-1}$, which corresponds to a much higher protein concentration (>100 $\mathrm{mg} \mathrm{ml}^{-1}$ ) inside the PEO domains after the film is prepared. Importantly, the PEGylated protein was very robust in this mixed solvent, even in the absence of protection from the amphiphilic block copolymer, as evident by TEM of structurally intact protein rings deposited on a grid from the mixed solvent (Fig. 1). Fig. 1 clearly also illustrates a propensity for the protein to aggregate into higher order structures under these conditions. Stacks, chains and disordered aggregates were observed, all with structurally intact rings. This is likely to be an effect of the solvent and the location of the PEG chains (lysine residues, to which the PEG chains are attached, are not present at the subunit or protein/protein interfaces) along with the natural propensity for $\operatorname{Lsm} \alpha$ to stack. $^{40}$

The polymer was spin coated into thin films on gold coated substrates with a thickness of $25 \mathrm{~nm}$ (measured by ellipsometry, data not shown) and annealed in water and benzene vapor to create vertically aligned hexagonally packed cylinders. The initial annealing with only water present served to ensure swelling of the PEO domains with water vapor to protect the protein. The same solvent mix and annealing conditions were 


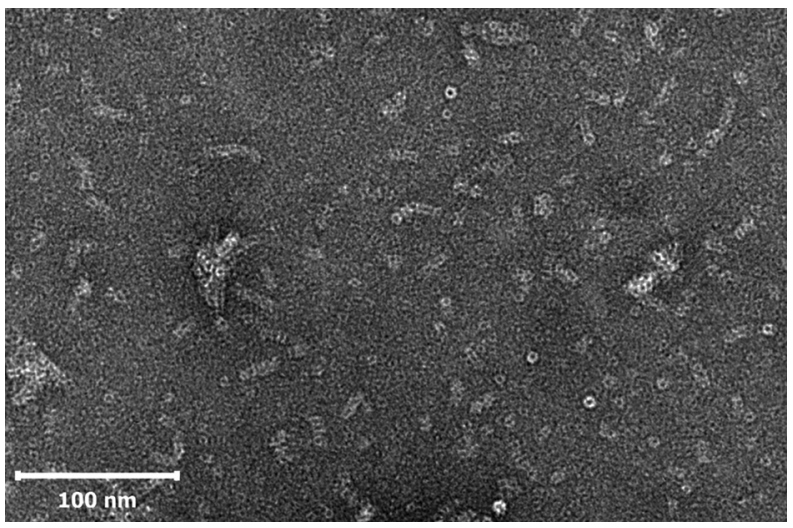

Fig. 1 TEM of Lsm $\alpha$ PEG dissolved in control solvent and deposited on carbon coated grid and stained by uranyl acetate.
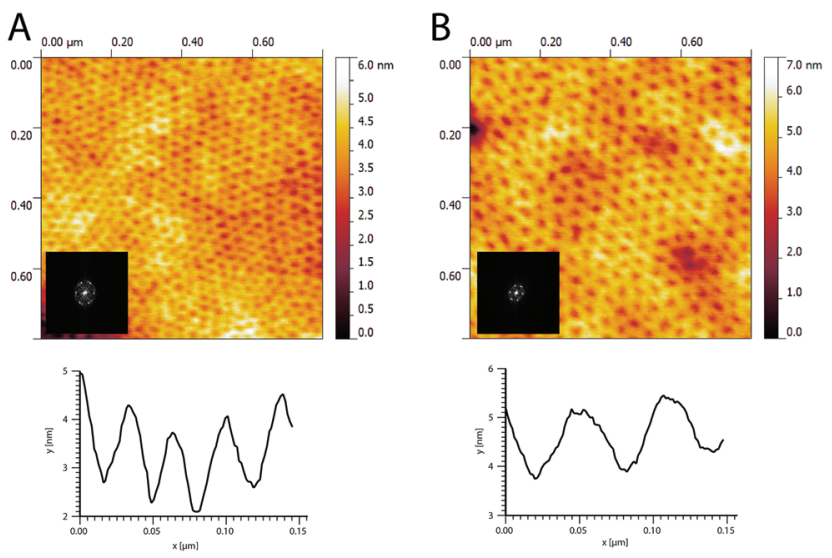

Fig. 2 AFM height images of PS- $b$-PEO without (A) and with (B) protein (Lsm $\alpha$ PEG), with corresponding line-scans (below) and power spectra (inserts). The films were prepared on gold by spincoating using identical conditions. The inserts represent the central portion $\left(0.2 \mu \mathrm{m}^{-1}\right.$ wide $)$ of the power spectrum (calculated 2D fast fourier transform) - which confirms the hexagonal lattice.

used for samples with and without protein. AFM confirm ordered films in both these cases, with an overall increase in PEO domain spacing when the protein was incorporated in the film (Fig. 2a and b). A further control using free PEG (2 kDa), instead of Lsm $\alpha$ PEG, confirmed that this effect was due to the protein rather than mainly being an effect of the protein PEGylation, with a smaller increase in domain spacing seen for the PEG control (ESI Fig. S2†). The inserts in Fig. 2 show the central portion of the power spectrum of each image and demonstrate the presence of a characteristic spacing, and hexagonal packing. The films were uniform over a reasonably long range; a $2 \mu \mathrm{m}$ scan can be seen in Fig. S3. $\dagger$

The AFM height images consistently portray the PEO domains as depressions of about $1 \mathrm{~nm}$ in the surrounding PS matrix (larger for the PEG control Fig. S2 $\dagger$ ). This has previously been interpreted as being due to crystallization of the PEO after being annealed in a swollen state, due to the low glass transition temperature of $\mathrm{PEO}\left(\begin{array}{lll}-17 & & \\ \end{array}\right.$ others have interpreted the phase contrast, which revealed that the PEO was softer than the PS, as evidence against PEO crystallization. ${ }^{42}$ In our case, we see both depressions and a phase signal indicating that the cylindrical domains were the softer domains (Fig. 2 and 3b), which we interpret as an effect of dehydration rather than crystallization of the PEO domains which were swollen during the solvent annealing.

The phase signal in tapping mode AFM contains information regarding the mechanical properties of the material, if imaging occurs in the repulsive mode, where higher phase values relate to more dissipated energy - i.e. a softer material. Importantly, a phase shift occurs as imaging moves from the attractive mode (light tapping) into the repulsive mode (moderate to hard tapping) as seen in Fig. 3a and b. Fig. 3b was acquired in air in the repulsive mode and clearly show that the cylindrical domains were dissipating more energy than the surrounding polystyrene, indicating that they were softer, confirming that this was in fact the $\mathrm{PEO}^{53}$ as expected.

To shed more light on the properties of the polystyrene and poly(ethylene oxide) domains the samples were also imaged by AFM in aqueous solution. The images acquired in liquid (phosphate buffered saline) showed initially well-ordered films that suffered from local delamination and bubbling within tens of minutes (Fig. $3 c$ and d PS- $b$-PEO after 60 min liquid exposure). This can be attributed to water penetrating films through either defects or through the water soluble PEO domains. Phase imaging confirmed the delamination of an ordered film, rather than disordering of the film, by recording the hexagonal phase across these larger bubbles. The bubbles were commonly seen to originate from defects, but also occurred in seemingly defect-free areas. For the protein containing sample, images were recorded as soon as possible after the addition of the liquid (11 min, Fig. 3f), and subsequently every 5 minutes until $100 \mathrm{~min}$. It is clear from the images in Fig. $3 g$ and $h$ that the initially observed hexagonal structure is obscured by protein leaching out from the film over time. The corresponding phase images show the protein aggregates more clearly than the height images, due to the significant increase in the phase signal (which therefore appears brighter) of the protein, most likely due to the protein being softer than the polymer surface. The entire timesequence is available in Fig. S6-8. $\uparrow$ This provides critical information regarding the presence of the protein in the water soluble PEO domains of the film, and regarding the rate of leaching. The protein appeared to leach out of the film quickly, with little change observed after the initial half an hour, although the challenges in imaging protein on soft polymer films make it difficult to directly measure the rate of the leaching.

X-ray Photoelectron Spectroscopy (XPS) was performed of thin films with or without protein. The chemical composition, 

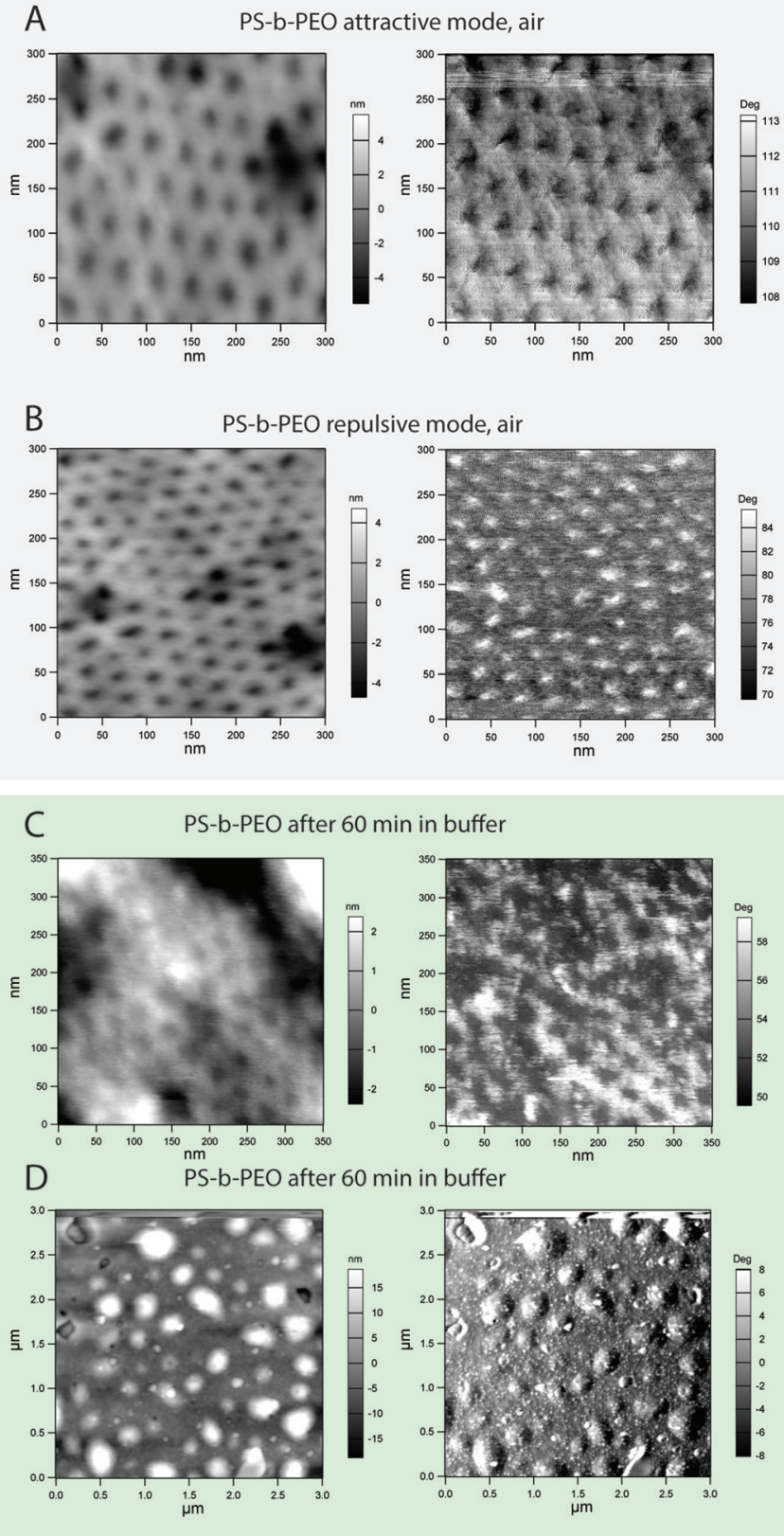
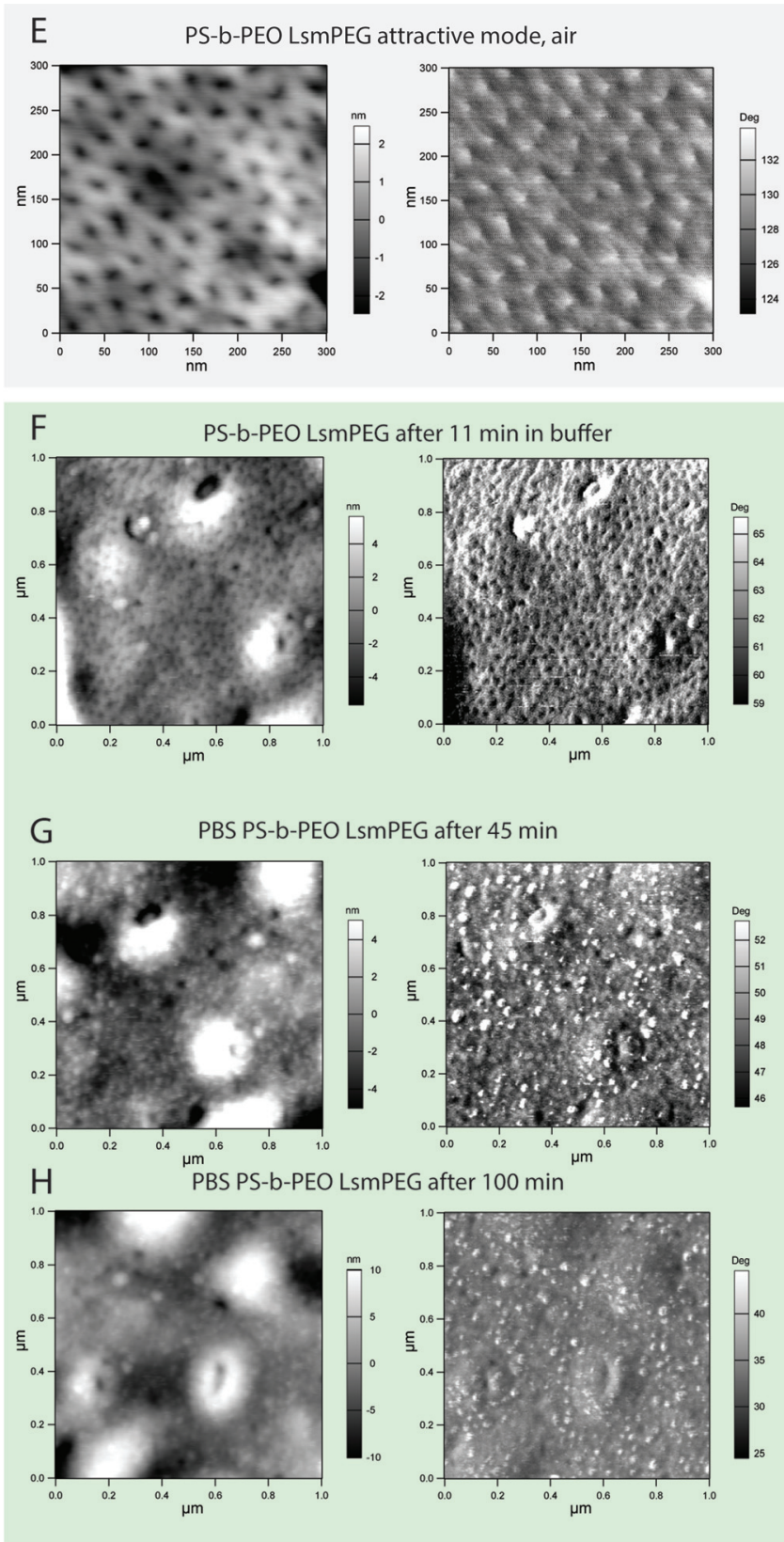

Fig. 3 Comparison of PS- $b$-PEO (A-D) and PS- $b$-PEOLsm $\alpha$ PEG (E-H) films by AFM in air (A, B, E) and in buffer (C, D, F-H). The time the sample has been in contact with the buffer is indicated for each set of images. Topography (left) and phase (right) images are presented in each case. Scans are $0.3 \mu \mathrm{m}$ wide in $\mathrm{A}-\mathrm{C}$ and $1 \mu \mathrm{m}$ wide in $\mathrm{E}, \mathrm{F}-\mathrm{H}$ and $3 \mu \mathrm{m}$ wide in $\mathrm{D}$.

and the components assigned to the carbon 1s spectra is presented in the ESI (Tables S1 and S2 and Fig. S4 $\dagger$ ). No nitrogen was detected from the protein containing film, which shows that the protein is not exposed to the surface of the film but buried within the PEO domains (as expected), while nitrogen was detected after leaching of the protein. Protein in the film could also not be detected via FTIR or Raman spectroscopy (data not shown). Thus, we rely on imaging to show the presence and location of the protein in the film.
In a separate experiment, films were exposed to a water droplet on top of the film for several hours after which the drop on the sample was allowed to evaporate before imaging by AFM in air. The dried PS- $b$-PEO film remained ordered and the delaminated bubbles disappeared as a result of solvent evaporation (Fig. 4a and c-zoom). In the case of the protein containing sample, clear evidence of protein having leached out of the film was seen (Fig. $4 \mathrm{~b}$ and $\mathrm{d}-$ zoom) with protein deposits mainly on top of the polystyrene as expected (due to the protein repelling properties of PEO surfaces ${ }^{54}$ ), see also 

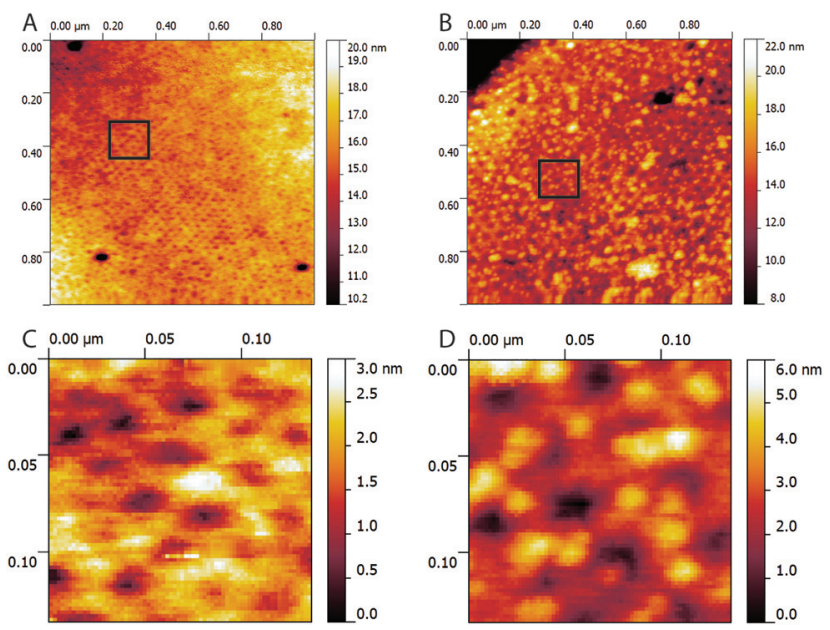

Fig. 4 AFM height images taken in air of PS- $b$-PEO (A, C - zoom) and PS- $b$-PEOLsm $\alpha$ PEG (B, D - zoom) after leaving the films with water drop on top followed by evaporation of the drop. Protein is clearly seen having leached out in $B$ and $D$.

PS- $b$-PEO with protein deposited on top of the film as a comparison in Fig. $\mathrm{S} 9, \dagger$ where protein can also clearly be seen on top of the film. This comparison clearly shows that the protein did not segregate out to the top of the film during the normal co-assembly conditions (Fig. 2b). It also shows that the protein in fact adsorbed preferentially to the PS domains as expected due to the protein repellent nature of the PEO. ${ }^{54-57}$

The expansion of the PEO domains due to protein incorporation and the leaching of the protein during water exposure of the film together confirm the successful incorporation of the protein into the PEO domains. However, as the protein was inside the PEO domains, it could not be directly imaged by AFM before leaching. TEM provides alternative information as it probes through the entire film. Reasonably ordered films could be achieved by simply dip coating TEM grids in the polymer or polymer/protein solutions. The grids were annealed as thin films and stained by $\mathrm{RuO}_{4}$ vapor. Fig. S10† shows films prepared by dip coating with and without the protein. The ordering in the material was inferior to that of thin films on gold imaged by AFM, but interestingly the ring shaped protein is visible in the PEO domains of the protein containing sample. The $\mathrm{RuO}_{4}$ stains the PEO at a higher rate than the PS domains, and also importantly serves to fix the film and make it less susceptible to beam damage. $^{58}$

As we wanted to avoid exposing the protein to strong acid and also we were not able to deposit the films on silicon wafers (due to surface chemistry incompatibility with the mixed solvent) to enable film lift-off via $\mathrm{HF}$, we spin coated the material onto carbon coated mica. Carbon coated mica proved a good match of surface chemistry and enabled rapid lift-off in water after solvent annealing. ${ }^{59}$ Fig. 5 shows the improved ordering achieved using this method and images of
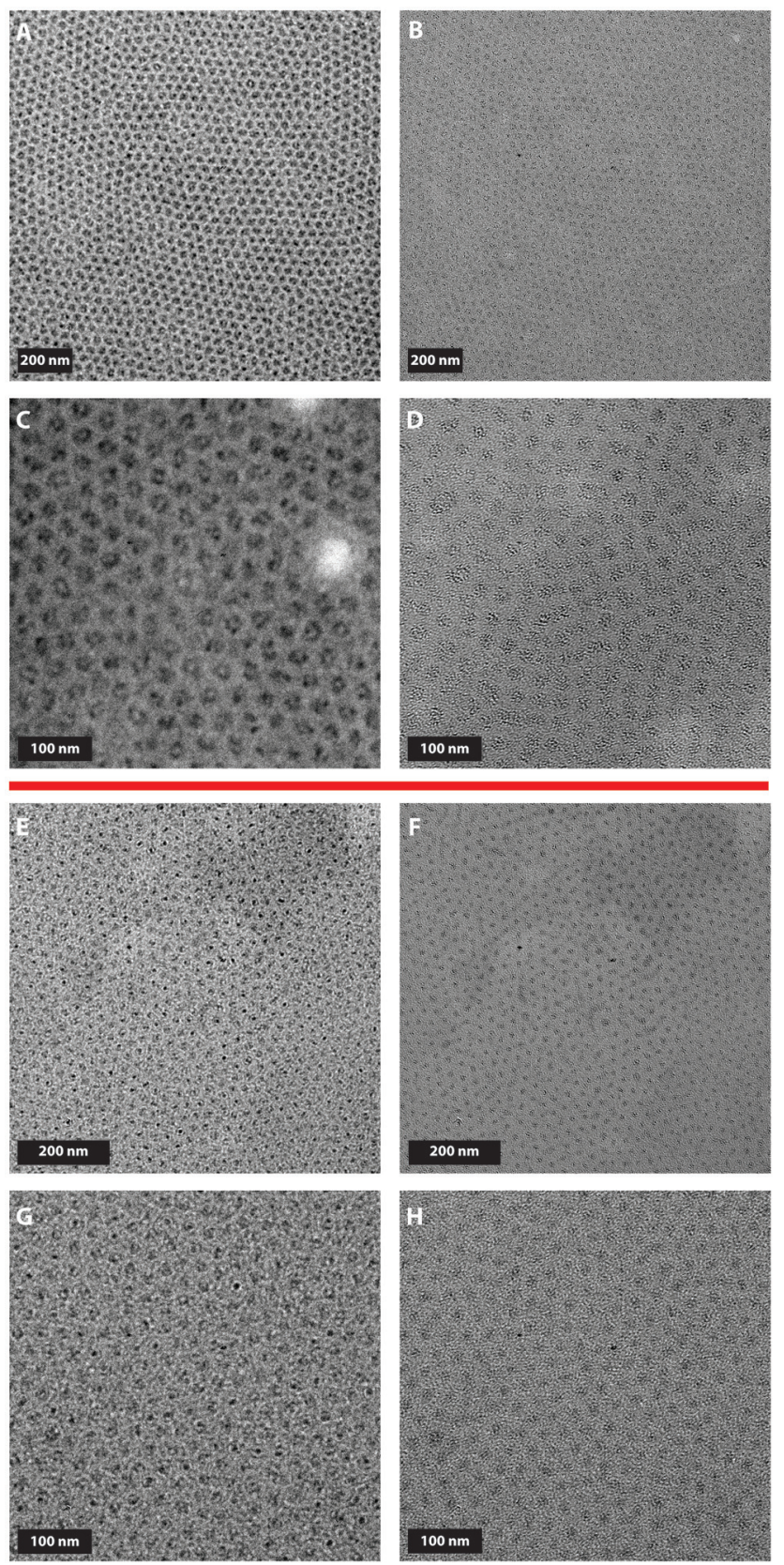

Fig. 5 TEM images of films spun onto carbon coated mica, lifted to $\mathrm{Cu}$ grid and stained with $\mathrm{RuO}_{4}$ vapour. A-F represent images of protein containing film, while images $\mathrm{E}-\mathrm{H}$ are of PS- $b$-PEO without protein. $\mathrm{A}$, $C, E$ and $G$ (left column) are aquired at significant overfocus (approximately $10 \mu \mathrm{m}$ ), while images $B, D, F$ and $H$ are aquired close to true focus or at slight underfocus (up to $2 \mu \mathrm{m}$ ).

$\mathrm{RuO}_{4}$ stained films acquired at different relative focus reiterate the increase in spacing and PEO size. Furthermore, TEM clearly revealed larger size and shape distribution of the PEO domains when the protein was incorporated, along with evidence of matter inside the PEO domains that stained more similar to the PS than the PEO. This is interpreted as protein, but the contrast in the images is limited, especially close to 
true focus. In fact, the domain spacing was easiest to see when imaging with severe over focus, which may lead to artefacts. Image artefacts were also seen to arise from extended exposure to the electron beam and granularity from the staining and the underlying carbon film further limit the image clarity. Fig. 5 presents images at different magnifications and in either over focus or close to focus for each magnification of both PS- $b$-PEOLsm $\alpha$ PEG and PS- $b$-PEO. To guide the eye, yellow dots have been overlaid to indicate the hexagonal pattern. By manually measuring PEO center to center distances in images, an approximate spacing of $25.7 \pm 0.3 \mathrm{~nm}$ without protein and $39.9 \pm 1.3 \mathrm{~nm}$ with the protein was calculated quantifying the apparent increase in PEO spacing to $14 \mathrm{~nm}$, which is in good agreement with the incorporation of Lsm $\alpha$ PEG $(7 \mathrm{~nm}$ in diameter + contribution from PEGylation).

As the images in Fig. 5 were captured in a focus series, beam damage may be present. Fig. 6 features images acquired according to a low-dose regime of grids tilted $40^{\circ}$. The expansion of the PEO domains can clearly be seen in the protein containing sample, and the irregular shapes of the protein filled PEO domains is emphasized in the tilted image. Deposits of ring-shaped, structurally intact, LsmoPEG can clearly be seen inside the PEO domains in Fig. 6. The protein assemblies are present in various shapes, with some elongated protein stacks evident. The protein is not as clearly resolved as when imaged separately on a grid (compare to Fig. 6d, for Lsm $\alpha$ PEG deposited from solvent and displayed on the same scale as the
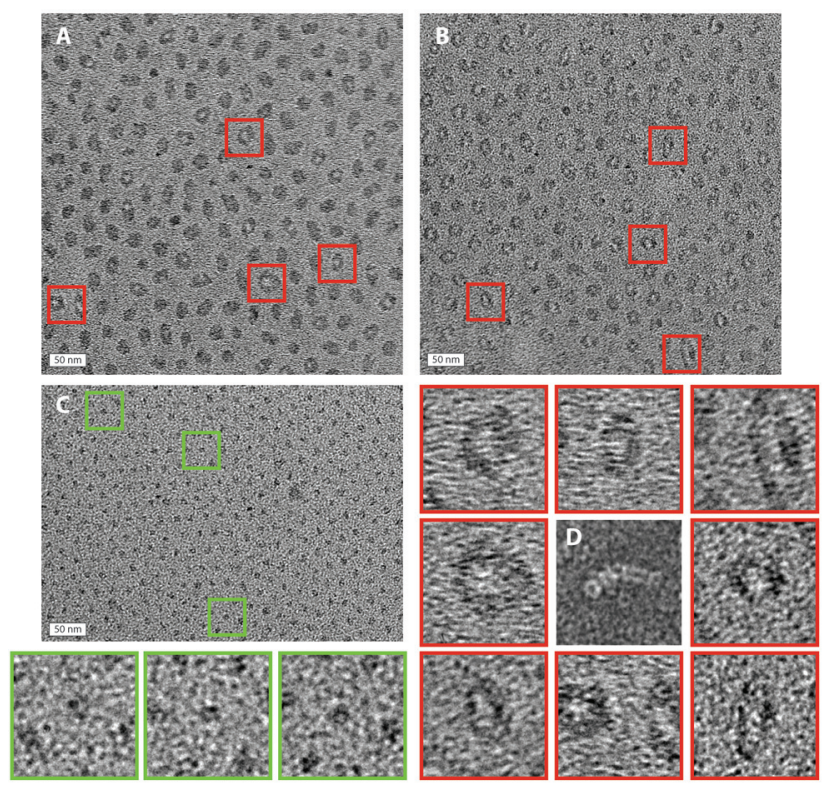

Fig. 6 Low dose TEM images at $40^{\circ}$ tilt of PS- $b$-PEOLsm $\alpha$ PEG (A-B) and PS- $b$-PEO (C) prepared on carbon coated mica and lifted to TEM grid before staining with $\mathrm{RuO}_{4}$, and enlarged areas (all $50 \mathrm{~nm}$ wide) of protein containing film (red) and PS- $b$-PEO (green) as well as Lsm $\alpha$ PEG (D) deposited on carbon coated grid from solvent (benzene, methanol, water as used for polymer samples) and stained with uranyl acetate and imaged without tilt. other zoomed-in images), but the size and shape is in good agreement.

In order to further study the morphology of the samples, high-angle annular dark-field scanning transmission electron microscopy (HAADF-STEM) was employed. In STEM, the beam of electrons is focused into a narrow spot, which is rastered across the sample. Incoherent elastic scattered electrons are detected to form the HAADF-STEM images, which means that the HAADF-STEM images are atomic number contrast images with a contrast inverted compared to TEM bright field images. A direct consequence of this is also that staining of samples is less vital in S-TEM. For the PS- $b$-PEO films imaged here though, the unstained films remained too unstable under the beam, even though the contrast of the unstained films was excellent in S-TEM. Fig. 7 shows S-TEM images of PS- $b$-PEOLsm $\alpha$ PEG (a) and the control PS- $b$-PEO (b) and the central portion of their corresponding power spectrum.

As it can be seen in Fig. 7, HAADF-STEM very clearly images individual PEO domains. The size and shape of these domains was seen to change upon the inclusion of protein. In many of the PEO domains, evidence of protein is seen. Some PEO domains in the protein-containing sample clearly remain of similar size and shape as the sample without protein, which indicates that those did not incorporate protein. The darker spots inside the PEO domains were manually measured to $9 \pm 2 \mathrm{~nm}$ (as compared to the $7 \mathrm{~nm}$ diameter of Lsm $\alpha$ prior to PEGylation). Distance determination from the power spectrum measured an average center-to-center distance of $22.3 \pm 0.8 \mathrm{~nm}$ for the control (Fig. 7b) and $35.5 \pm 2.2 \mathrm{~nm}$ for the protein containing film (Fig. 7a).

Previous studies have shown a mixed effect on the domain size after incorporation of material in the films, with a decrease in PEO domain size upon inclusion of peptides or myoglobin-PEG into PS- $b$ - EEO $^{11}$ but a significant increase $(10 \mathrm{~nm})$ upon incorporation of ferritin-polymer conjugates. ${ }^{9}$ The incorporation of cylindrical peptide nanotubes $(1 \mathrm{~nm}$ in diameter) in PS- $b$-PMMA was found to increase the lateral spacing by $3 \mathrm{~nm}$. It is not surprising that the incorporation of a larger entity, such as a heptameric protein in our case (diameter $7 \mathrm{~nm}$ ) yields a larger increase of spacing.

We have established protocols and explored characterization methods for these protein/polymer composite samples utilizing a unique stackable protein ring. The work here builds on previous studies using model protein such as ferritin ${ }^{9}$ (which was nicely demonstrated to reside in the PEO domains) and myoglobin $^{11}$ (which has a strong UV-spectrum and enzymatic activity to employ for characterization). Future fine tuning of the assembly of the higher order Lsm $\alpha$ stacks within the PEO nanocontainers, along with the prospect of functionalizing the protein structures with for example noble metal particles opens up the possibility of exciting applications as functional electronic or optical materials. Furthermore, the studied leaching of the PEO incorporated protein is of relevance for drug delivery applications, where the release rate is expected to be tunable through crosslinking or additional overlayers. 

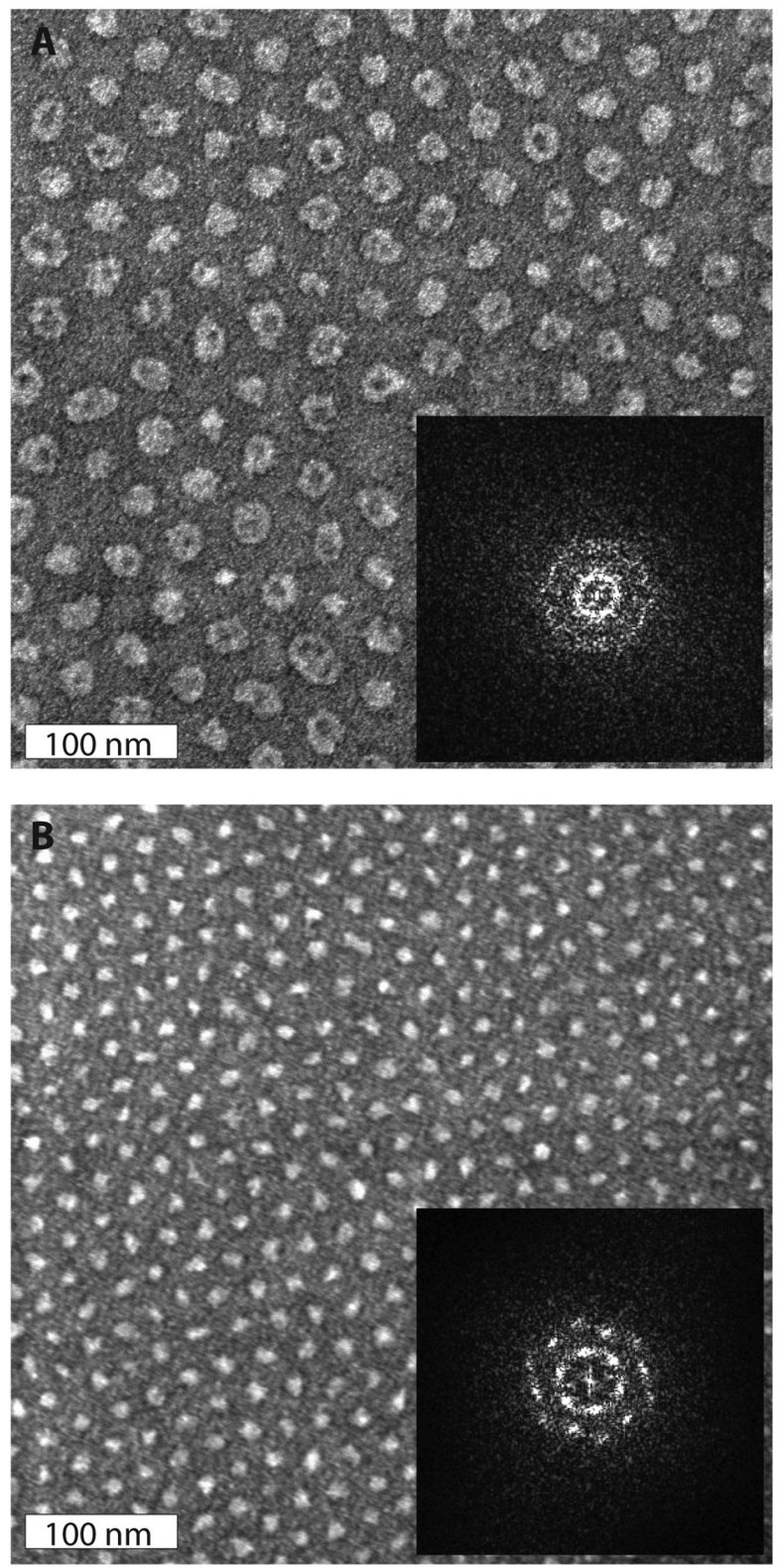

Fig. 7 HAADF-STEM images of PS- $b$-PEOLsm $\alpha$ PEG (A) and PS- $b$-PEO (B) stained by $\mathrm{RuO}_{4}$. The insets show a cropped area of the power spectrum of each image (calculated 2D fast fourier transform) - used to determine the PEO center-to-center spacing.

\section{Experimental}

\section{Expression and purification of Lsm $\alpha$}

The Lsm $\alpha$ gene from Methanobacterium thermoautotrophicum was synthesized (Epoch Life Science, Texas) and obtained as expression ready inserts cloned in the pGEX-4T-2 vector. The plasmids were transformed into Escherichia coli BL21 cells (Life Technologies) for protein expression and purified using standard methods. ${ }^{60}$

\section{Protein PEGylation}

Purified Lsm $\alpha$ was incubated with equimolar ratio of $2 \mathrm{kDa}$ PEG (Sunbright巴 ME-020CS) to lysine and stirred at room temperature for 10 minutes. The reaction was quenched by lowering the $\mathrm{pH}$ to 5. Lsm $\alpha$ PEG was separated from the mixture by size exclusion chromatography on a Superdex 200 10/300 GL column (Life Technologies) pre-equilibrated with PBS pH 7.3.

\section{Sample preparation}

Silicon wafers (100, P-type B-doped, institute of electronic materials technology) were cleaned by pirahna (3:7 $\mathrm{H}_{2} \mathrm{O}_{2}: \mathrm{H}_{2} \mathrm{SO}_{4}$, warning piranha is very corrosive - take extreme care) overnight followed by extensive rinsing in ultra-pure water, drying by $\mathrm{N}_{2}$ and further cleaning by reactive oxygen plasma ( $50 \%$ pore opening, $50 \mathrm{~W}, 5 \mathrm{~min}$ ). Silicon wafers were either used directly for film deposition or after sputter coating (Kurt J Lesker DC/RF sputter coater) of gold (200 W, 3.1 mTorr Ar, $3 \mathrm{~min}$ ) with a titanium adhesion layer $(140 \mathrm{~W}, 5.4 \mathrm{mTorr}$ Ar, $5 \mathrm{~min}$ ). Gold coated samples were further pirahna cleaned before use. Carbon coated mica was prepared by subjecting freshly cleaved mica to carbon deposition using an Edwards Auto 306 carbon evaporator as published previously. ${ }^{59}$

\section{Thin film deposition}

Poly(styrene- $b$-ethylene oxide) $\left(M_{\mathrm{n}} \times 10^{3}\right.$ S- $b$-EO 18.0- $b$-7.5) from Polymer Source Inc., Canada, was dissolved in benzene (AR) at a concentration of $1 \%$. Thin films were prepared by spin coating (Laurell technologies corporation, US, spin speed 1000-5000 rpm, $3 \mathrm{~min}$ ). Anisole, toluene and dichloromethane were also explored as spin coating solvents. For protein containing films $0.04 \mathrm{mg}$ PEGylated Lsm $\alpha$ was dissolved in $6 \mu \mathrm{l}$ methanol/water mix ( $80 \%$ methanol, $20 \%$ water), followed by the addition of $16 \mu \mathrm{l}$ methanol and finally $54 \mu \mathrm{l}$ 1\% PS- $b$-PEO in benzene (final solvent has a composition of $71.7 \%$ benzene, $26.9 \%$ methanol and $1.4 \%$ water). Corresponding control samples without protein was made up using the same solvent composition. The resulting clear solution was spin coated as above. The films were solvent annealed by leaving samples in a closed chamber with water on the bottom for $1.5 \mathrm{~h}$, after which an equal volume of benzene was added and samples left to anneal for a further 6 hours at room temperature. The distance between samples and solvent was $5 \mathrm{~cm}$ and the total chamber volume was $450 \mathrm{~cm}^{3}$.

\section{X-ray photoelectron spectroscopy}

(XPS) data were collected on a Kratos Axis UltraDLD equipped with a hemispherical electron energy analyzer. Spectra were excited using monochromatic Al K $\alpha$ X-rays (1486.69 eV) with the X-ray source operating at $150 \mathrm{~W}$. Survey scans were collected with a $160 \mathrm{eV}$ pass energy, while core level scans were collected with a pass energy of $20 \mathrm{eV}$. The analysis chamber was at pressures in the $10^{-9}$ Torr range throughout the data collection. Data analysis was performed using CasaXPS software. Shirley backgrounds were used in the peak fitting. 
Quantification of survey scans utilized relative sensitivity factors supplied with the instrument. Core level data were fitted using Gaussian-Lorentzian peaks (30\% Lorentzian). Values of elemental composition presented represent the average \pm standard deviation (sd) of 3 scans in different spots on the same film, while the values presented for the protein powder were acquired in one spot only. Core level data of $\mathrm{O}, \mathrm{N}$ and $\mathrm{C}$ were recorded in one spot per sample.

\section{Imaging}

Atomic Force Microscopy (Digital Instruments, Nanoscope IIIa) in air, using tapping mode with NSG 01 probes (resonance frequency $\approx 150 \mathrm{kHz}$ ) from NT-MDT (Russia) was used to image the films after solvent annealing. AFM in liquid was performed on an Asylum Research MFP-3D system (Santa Barbara, CA, USA) using DNP-S-10 probes (Bruker, US, cantilever $\mathrm{C}$, force constant $0.24 \mathrm{~N} \mathrm{~m}^{-1}$ ) for tapping in liquid or Tap 300-G probes (budget sensors, Bulgaria), force constant $40 \mathrm{~N} \mathrm{~m}^{-1}$, for initial images in air. Transmission Electron Microscopy (TEM) was used to view protein directly deposited on grids as well as polymer films with or without protein. Polymer films were deposited on grids either by dipcoating or by floating films spun coated on carbon coated mica onto the surface of water, from where the films were picked up with the TEM grids. ${ }^{59}$ Films were stained with $\mathrm{RuO}_{4}$ vapour $\left(0.5 \% \mathrm{RuO}_{4}\right.$ in water from Electron Microscopy Sciences, US) or uranyl acetate (Sigma). TEM imaging was performed on an FEI Tecnai 12 electron microscope operated at $120 \mathrm{kV}$. Digital electron micrographs were recorded on a Gatan UltraScan 1000 CCD camera. STEM was performed on an FEI Tecnai F20 electron microscope operated at $200 \mathrm{kV}$ and equipped with a high angle annular dark field detector. Center-to-center distances were calculated from bright field TEM imaged by manually measuring distances in images using photoshop. The values presented in the results section represent the average $( \pm \mathrm{sd})$ of the average distance determined for a number of images (7 images protein containing, 4 images for the control), where the distance for each image was determined from 20-40 measurements. Corresponding distances for HAADFSTEM images were determined by measurements in the power spectrum (Image J calculated 2D Fast Fourier Transform). The position of the first order peak (closest to the center) was determined in Image $\mathrm{J}$ in all directions of the hexagonal lattice (6 measurements per image). The data presented in the paper represent the average \pm sd of 12 measurements for the control ( 2 images, 6 positions in each) and 36 measurements for the protein containing sample (6 images, 6 positions in each).

\section{Conclusions}

We have used the self-assembly of PS- $b$-PEO to sequester stackable protein rings to the hexagonally packed PEO domains. This creates ordered thin films which were imaged by AFM and TEM to show an expansion of the PEO packing parameter upon the inclusion of the protein. AFM was also used to image protein leaching out of the PEO domains when the films were exposed to aqueous solutions, and TEM was able to clearly image protein deposits inside the PEO domains, forming higher order structures of various shapes. Future functionalization of protein stacks organized at a surface by block copolymer self-assembly opens up the exciting possibility of applications as functional electronic or optical materials.

\section{Acknowledgements}

The MacDiarmid Institute for Advanced Materials and Nanotechnology is acknowledged for funding of this project. Adrian Turner is acknowledged for advice and technical assistance with TEM and carbon coating. Thanks to Dr Colin Doyle for XPS acquisition, to Dr Duncan McGillivray and Rayomand Shahlori for ellipsometry instruction and fruitful discussions, to Daniel Verdon, Rayleen Fredericks and Prof. Conan Fee for help with protein PEGylation and purification and to Matt Pendred for graphic design. Bridget Mabutt, Macquarie University, is gratefully acknowledged for expertise in Lsm structural biology.

\section{References}

1 T. Trindade, P. O’Brien and N. L. Pickett, Chem. Mater., 2001, 13, 3843-3858.

2 P. V. Kamat, J. Phys. Chem. C, 2007, 111, 2834-2860.

3 J. G. Kennemur, L. Yao, F. S. Bates and M. A. Hillmyer, Macromolecules, 2014, 47, 1411-1418.

4 A. Nunns, J. Gwyther and I. Manners, Polymer, 2013, 54, 1269-1284.

5 H. C. Kim, S. M. Park and W. D. Hinsberg, Chem. Rev., 2010, 110, 146-177.

6 Y. Lin, A. Boker, J. B. He, K. Sill, H. Q. Xiang, C. Abetz, X. F. Li, J. Wang, T. Emrick, S. Long, Q. Wang, A. Balazs and T. P. Russell, Nature, 2005, 434, 55-59.

7 J. Malmström and J. Travas-Sejdic, J. Appl. Polym. Sci., 2014, 131.

8 H. Tran, K. Ronaldson, N. A. Bailey, N. A. Lynd, K. L. Killops, G. Vunjak-Novakovic and L. M. Campos, ACS Nano, 2014, 8, 11846-11853.

9 Y. Hu, D. Samanta, S. S. Parelkar, S. W. Hong, Q. Wang, T. P. Russell and T. Emrick, Adv. Funct. Mater., 2010, 20, 3603-3612.

10 Y. Hu, D. Chen, S. Park, T. Emrick and T. P. Russell, Adv. Mater., 2010, 22, 2583-2587.

11 A. D. Presley, J. J. Chang and T. Xu, Soft Matter, 2011, 7, 172-179.

12 B. Kim, C. N. Lam and B. D. Olsen, Macromolecules, 2012, 45, 4572-4580.

13 D. B. Haddow, D. A. Steele, R. D. Short, R. A. Dawson and S. MacNeil, J. Biomed. Mater. Res., Part A, 2003, 64, 80-87. 
14 D. M. Hess, R. R. Naik, C. Rinaldi, M. M. Tomczak and J. J. Watkins, Chem. Mater., 2009, 21, 2125-2129.

15 A. M. Rosales, B. L. McCulloch, R. N. Zuckermann and R. A. Segalman, Macromolecules, 2012, 45, 6027-6035.

16 J. P. Billot, A. Douy and B. Gallot, Makromol. Chem., Macromol. Chem. Phys., 1976, 177, 1889-1893.

17 A. Douy and B. Gallot, Polymer, 1982, 23, 1039-1044.

18 C. S. Thomas, M. J. Glassman and B. D. Olsen, ACS Nano, 2011, 5, 5697-5707.

19 C. S. Thomas, L. Xu and B. D. Olsen, Biomacromolecules, 2012, 13, 2781-2792.

20 S. M. Douglas, H. Dietz, T. Liedl, B. Hogberg, F. Graf and W. M. Shih, Nature, 2009, 459, 414-418.

21 P. W. K. Rothemund, Nature, 2006, 440, 297-302.

22 W. M. Shih, J. D. Quispe and G. F. Joyce, Nature, 2004, 427, 618-621.

23 J. A. Gerrard, Protein Nanotechnology: Protocols, Instrumentation and Applications, Humana Press, 2nd edn, 2013.

24 S. Howorka, Curr. Opin. Biotechnol., 2011, 22, 485-491.

25 I. Cherny and E. Gazit, Angew. Chem., Int. Ed., 2008, 47, 4062-4069.

26 T. P. J. Knowles and M. J. Buehler, Nat. Nanotechnol., 2011, 6, 469-479.

27 M. D. R. Peralta, A. Karsai, A. Ngo, C. Sierra, K. T. Fong, N. R. Hayre, N. Mirzaee, K. M. Ravikumar, A. J. Kluber, X. Chen, G. Y. Liu, M. D. Toney, R. R. Singh and D. L. Cox, ACS Nano, 2015, 9, 449-463.

28 L. Sasso, S. Suei, L. Domigan, J. Healy, V. Nock, M. A. K. Williams and J. A. Gerrard, Nanoscale, 2014, 6, 1629-1634.

29 S. Zhang, Nat. Biotechnol., 2003, 21, 1171-1178.

30 J. D. Brodin, J. R. Carr, P. A. Sontz and F. A. Tezcan, Proc. Natl. Acad. Sci. U. S. A., 2014, 111, 2897-2902.

31 Y. T. Lai, D. Cascio and T. O. Yeates, Science, 2012, 336, 1129.

32 J. E. Padilla, C. Colovos and T. O. Yeates, Proc. Natl. Acad. Sci. U. S. A., 2001, 98, 2217-2221.

33 E. R. Ballister, A. H. Lai, R. N. Zuckermann, Y. Cheng and J. D. Mougous, Proc. Natl. Acad. Sci. U. S. A., 2008, 105, 3733-3738.

34 I. Medalsy, O. Dgany, M. Sowwan, H. Cohen, A. Yukashevska, S. G. Wolf, A. Wolf, A. Koster, O. Almog, I. Marton, Y. Pouny, A. Altman, O. Shoseyov and D. Porath, Nano Lett., 2008, 8, 473-477.

35 F. F. Miranda, K. Iwasaki, S. Akashi, K. Sumitomo, M. Kobayashi, I. Yamashita, J. R. H. Tame and J. G. Heddle, Small, 2009, 5, 2077-2084.

36 A. J. Phillips, J. Littlejohn, N. A. Yewdall, T. Zhu, C. Valéry, F. G. Pearce, A. K. Mitra, M. Radjainia and J. A. Gerrard, Biomacromolecules, 2014, 15, 1871-1881.

37 M. Ardini, F. Giansanti, L. Di Leandro, G. Pitari, A. Cimini, L. Ottaviano, M. Donarelli, S. Santucci, F. Angelucci and R. Ippoliti, Nanoscale, 2014, 6, 8052-8061.
38 D. N. Woolfson and Z. N. Mahmoud, Chem. Soc. Rev., 2010, 39, 3464-3479.

39 Z. N. Mahmoud, S. B. Gunnoo, A. R. Thomson, J. M. Fletcher and D. N. Woolfson, Biomaterials, 2011, 32, 3712-3720.

40 B. M. Collins, S. J. Harrop, G. D. Kornfeld, I. W. Dawes, P. M. G. Curmi and B. C. Mabbutt, J. Mol. Biol., 2001, 309, 915-923.

41 C. Mura, A. Kozhukhovsky, M. Gingery, M. Phillips and D. Eisenberg, Protein Sci., 2003, 12, 832-847.

42 Z. Q. Lin, D. H. Kim, X. D. Wu, L. Boosahda, D. Stone, L. LaRose and T. P. Russell, Adv. Mater., 2002, 14, 1373-1376.

43 S. H. Kim, M. J. Misner, T. Xu, M. Kimura and T. P. Russell, Adv. Mater., 2004, 16, 226-231.

44 S. H. Kim, M. J. Misner and T. P. Russell, Adv. Mater., 2004, 16, 2119-2123.

45 W. Gu, S. W. Hong and T. P. Russell, ACS Nano, 2012, 6, 10250-10257.

46 E. M. Freer, L. E. Krupp, W. D. Hinsberg, P. M. Rice, J. L. Hedrick, J. N. Cha, R. D. Miller and H. C. Kim, Nano Lett., 2005, 5, 2014-2018.

47 A. Labiano, M. Dai, W. S. Young, G. E. Stein, K. A. Cavicchi, T. H. Epps and B. D. Vogt, J. Phys. Chem. C, 2012, 116, 6038-6046.

48 M. K. Mayeda, J. Hayat, T. H. Epps and J. Lauterbach, J. Mater. Chem. A, 2015, 3, 7822-7829.

49 H. Sai, K. W. Tan, K. Hur, E. Asenath-Smith, R. Hovden, Y. Jiang, M. Riccio, D. A. Muller, V. Elser, L. A. Estroff, S. M. Gruner and U. Wiesner, Science, 2013, 341, 530-534.

50 T. G. Fitzgerald, R. A. Farrell, S. O’Driscoll, C. T. O’Mahony, J. D. Holmes and M. A. Morrisy, e-J. Surf. Sci. Nanotechnol., 2009, 7, 471-475.

51 S. Kim, R. M. Briber, A. Karim, R. L. Jones and H. C. Kim, Macromolecules, 2007, 40, 4102-4105.

52 J. N. L. Albert and T. H. Epps III, Mater. Today, 2010, 13, 24-33.

53 H. Wang, A. B. Djurišić, W. K. Chan and M. H. Xie, Appl. Surf. Sci., 2005, 252, 1092-1100.

54 I. Banerjee, R. C. Pangule and R. S. Kane, Adv. Mater., 2010, 23, 690-718.

55 P. Kingshott, H. Thissen and H. J. Griesser, Biomaterials, 2002, 23, 2043-2056.

56 P. A. George, M. R. Doran, T. I. Croll, T. P. Munro and J. J. Cooper-White, Biomaterials, 2009, 30, 4732-4737.

57 R. Nehring, C. G. Palivan, S. Moreno-Flores, A. Mantion, P. Tanner, J. Luis Toca-Herrera, A. Thunemann and W. Meier, Soft Matter, 2010, 6, 2815-2824.

58 J. S. Trent, J. I. Scheinbeim and P. R. Couchman, Macromolecules, 1983, 16, 589-598.

59 F. J. M. Roache, M. Radjainia, D. E. Williams, J. A. Gerrard, J. Travas-Sejdic and J. Malmström, Ultramicroscopy, 2015, 150, 71-73.

60 A. Wason, PhD thesis, Investigation of Lsm Proteins as Scaffolds in Bionanotechnology, University of Canterbury, 2014. 